
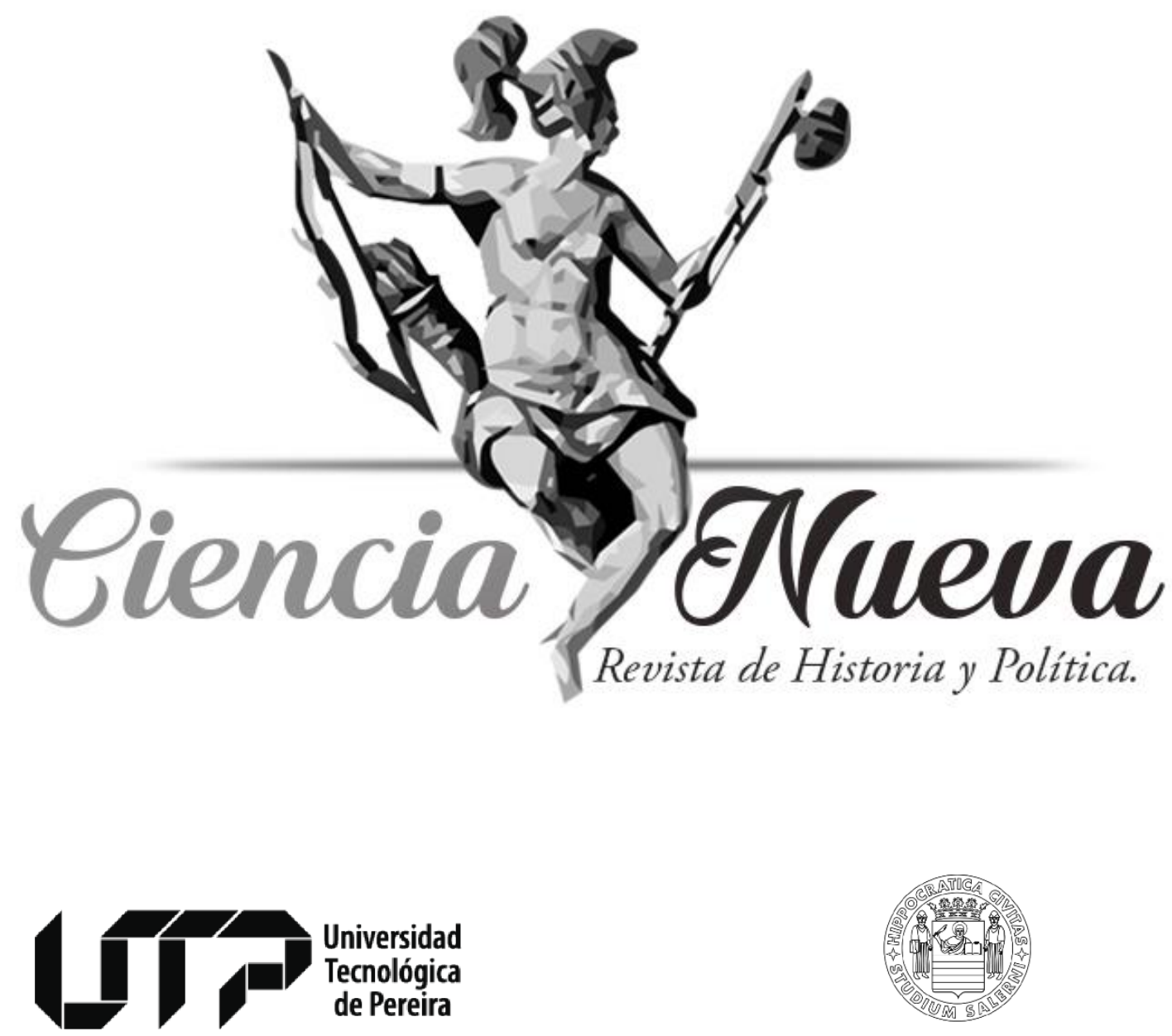

UNIVERSITÀ DEGLI STUDI DI SALERNO

Maestría en Historia

Maestría en Ciencia Política

ANALES Y MEMORIAS DEL CENTRO-OCCIDENTE COLOMBIANO

PROYECTO DE ACUERDO: POR EL CUAL SE DICTAN VARIAS DISPOSICIONES SOBRE ADQUISICIÓN DE TERRENOS CON DESTINO A UN PARQUE MUNICIPAL Y A LA CONSTRUCCIÓN DE ESCUELAS PRIMARIAS, CON MOTIVO DEL PRIMER CENTENARIO DE LA FUNDACIÓN DE LA CIUDAD. JULIO DE 1950, JORGE ROA MARTÍNEZ, ALCALDE. DRAFT OF AGREEMENT: WHICH ISSUES SOME PROVISIONS ABOUT THE ACQUISITION OF LANDS WHICH WILL BE SET ASIDE FOR THE BUILDING OF A TOWN PARK AND PRIMARY SCHOOLS, BECAUSE OF THE FIRST CENTENARY OF THE CITY'S FOUNDATION. JULY OF 1950, JORGE ROA MARTINEZ, MAJOR. Ciencia Nueva. Revista de Historia y Política pp. 209-213

Vol. $1 N^{o}$ 2, Julio-Diciembre de 2017 Pereira, Colombia 


\section{PROYECTO DE ACUERDO: POR EL CUAL SE DICTAN VARIAS DISPOSICIONES SOBRE ADQUISICIÓN DE TERRENOS CON DESTINO A UN PARQUE MUNICIPAL Y A LA CONSTRUCCIÓN DE ESCUELAS PRIMARIAS, CON MOTIVO DEL PRIMER CENTENARIO DE LA FUNDACIÓN DE LA CIUDAD. JULIO DE 1950, JORGE ROA MARTÍNEZ, ALCALDE. * DRAFT OF AGREEMENT: WHICH ISSUES SOME PROVISIONS ABOUT THE ACQUISITION OF LANDS WHICH WILL BE SET ASIDE FOR THE BUILDING OF A TOWN PARK AND PRIMARY SCHOOLS, BECAUSE OF THE FIRST CENTENARY OF THE CITY'S FOUNDATION. JULY OF 1950, JORGE ROA MARTINEZ, MAJOR.}

Ciencia Nueva, Revista de Historia y Política ciencianueva@utp.edu.co 1 documento que mostramos a los lectores de Ciencia Nueva, Revista de Historia y Política, corresponde a un proyecto de acuerdo presentado por el señor Jorge Roa Martínez al Consejo Municipal de la ciudad de Pereira, durante su primer año como alcalde de la ciudad, en julio de 1950. El original reposa en el libro de folios "Proyectos de Acuerdo presentados por el alcalde Jorge Roa Martínez en 1950", disponible en el archivo personal de Roa en el fondo patrimonial de la Biblioteca Jorge Roa Martínez de la Universidad Tecnológica de Pereira.

La importancia de publicar y difundir este documento histórico, radica en el hecho de que es un archivo cuya naturaleza se torna significativa en la medida en que permite dar cuenta de la visión de Jorge Roa Martínez ${ }^{1}$ sobre Pereira como una ciudad moderna que apuntaba a un notorio y acelerado crecimiento y urbanización desde la segunda mitad del siglo XX. En dicho contexto, también se hacía evidente - Roa logró captar esta evidencia- la necesidad de que la ciudad contara con espacios propicios para el esparcimiento, el aprovechamiento del tiempo libre y el ocio de sus ciudadanos, aspectos que cobran especial relevancia en la actualidad, cuando en el último año, en la esfera pública local se ha planteado

\footnotetext{
* Publicación y difusión de documento histórico. El presente artículo respeta las directrices y normas dispuestas en la Declaración de Ética de Publicación de Ciencia Nueva, Revista de Historia y Política. Esta declaración puede consultarse en la página web de la revista: revistas.utp.edu.co/index.php/historia

${ }^{1}$ El Dr. Jorge Roa Martínez fue miembro de la Sociedad de Mejoras de Pereira y socio fundador del Club Rotario en la misma ciudad. Fue fundador y primer rector de la Universidad Tecnológica de Pereira. Por todo ello, Roa es catalogado por algunos historiadores como un personaje cívico y cosmopolita. Para mayor ilustración sobre este particular, léase Álvaro Acevedo Tarazona, Diana María Rodríguez Herrera y Nelson Giraldo Mejía, Jorge Roa Martínez: memoria de una visión cosmopolita (Pereira: Editorial UTP, 2009), y Álvaro Acevedo Tarazona, Rigoberto Gil Montoya y Pablo Prado Gutiérrez, Universidad Tecnológica de Pereira: 40 años, una mirada a sus orígenes (Pereira: Editorial UTP, 2001).
} 
la discusión sobre cuál será el uso que se le dará a los predios del actual Batallón San Mateo, una vez éste sea trasladado a las inmediaciones del municipio de La Virginia.

Finalmente, se puede plantear una conclusión anticipada, en términos de que Roa Martínez y otras personalidades que eran cercanas a sus círculos de sociabilidad ${ }^{2}$, tenían claridades sobre el sentido de cómo debía planificarse una ciudad moderna. Claridades que en los tiempos que corren parecen diluirse entre los discursos y promesas políticas.

${ }^{2}$ Léase Guillermo Ángel Ramírez, Solar de Granos (Pereira: Editorial Gráficas Olímpica, 1995). 
H. H. Concejales :

Para algunas personas, el proyecto de realizar un parque, que merezca este nombre, será notivo de criticas $\mathrm{y}$ de escán dalo y lo calificarán de inútil suntuosidad.- Con todo, nada es más distracción del pueblo :

Puede afimarse que no se encuentra una ciudad moderna y de categoría que no disponga de un área verde y de gran am plitud y belleza para estos ab sus dias de descanso al aire libre, te millares de per deporte, encontrar espectáculos y comidas sanas para ju ar, hacer y para sus niños.- Los garitos, cantinas y lugares para vicio: han sufrido un colppso casi definitivo ante lo atracción de los grandes bosques, urbanos.-

Pasaron los tiempos en que los Parques eran lugares de privilegio, pare uso exclusivo de lis civenecidas y degenerados aristocracias de lins cortes reales, ahore los parques son paro todo el nundo" y sitios en donde se confunden en un mismo espiritu de mocrático todas li:s clases sociales.-

Pereira todavia dispone de terrenos miravillosos por su paisaje, árboles y aguas en sitios a propiados para llenar es ta finalidad $y$ que en cortos años quedarán dentro del perimetro urbanizado.- Perder estas reservas demorando su adquisición no sería prudente, ni económico.-

Su valor actual es varias veces mayor que el de ha ce algunos años atrás, pero lo sería todavía mayor y probablemente imposible en años venideros. -

Por esto se os solicita la aprobación de este pro yecto, que por otra pe e no implica una financiación en dinero y se os propone que a ut...ééis la venta de algunas propiedades Municí pales, hoy fuertemen: alorizadas e inútiles para el Fisco.- Reemplazando su valor por $\epsilon$ - de los terrenos para el Parque, haréis una obra de grandes repercusiones futuras y cuando menos harias buen ne. gocio propiedades beneficiadas, compensará cualquier inversión que se haga en éllas.-

$Y$ una vez adquirido el terreno veréis como dentro de él aparecerán restaurantes, canchas de deportes, piscinas, pase-
os, fuentes, distracciones de toda indole, donadas por las grandes firmas de la industria y del comercio como homenaje a la ciudad para su centenario.-

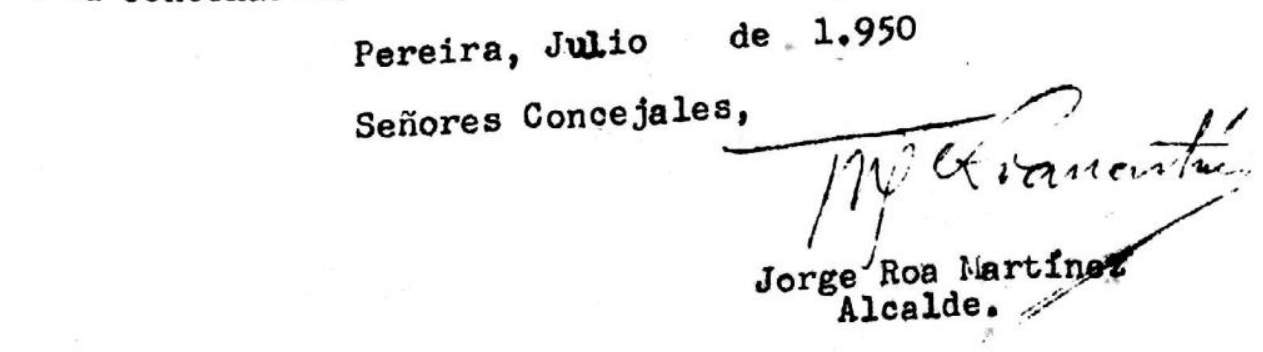

\section{Jaros/ocre}




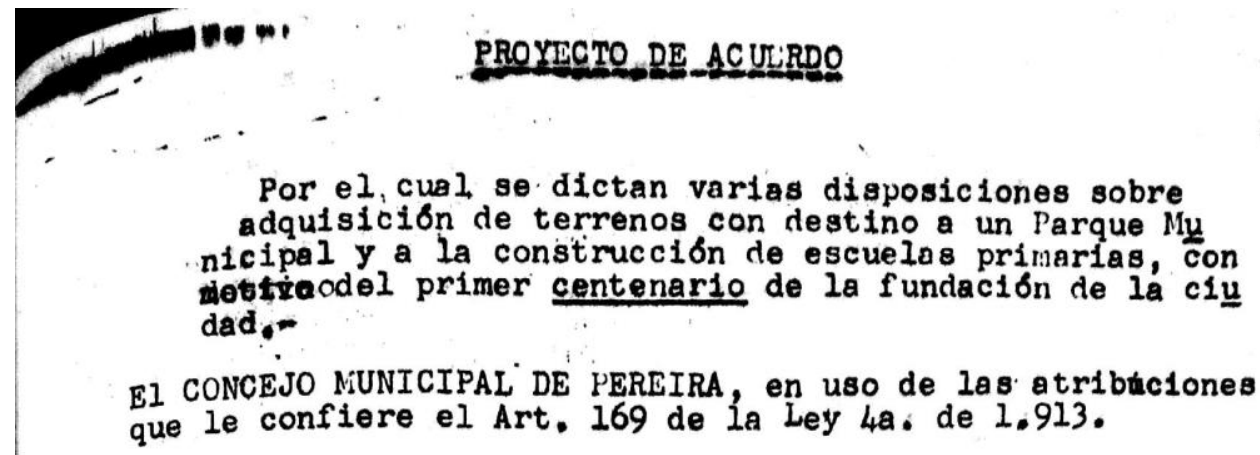

$$
\text { A C C U E } R \text { R D } A \text { : }
$$
Articulo $1^{\circ}=$ Declárase de utilidad pública la realización de un el cuał, por sus dimensiones, ubicación $y$ demás condiciones venga a el cuar las necesidades actuales y futuras de la ciudad y sirva de lu gar de recreo a los ciudadanos.-

rambién se decreta de utilidad pública la construcción de escuelas o grupos escolares en diferentes sectores urbanos y la adquísición de los terrenos necesarios para éllo.-

Articulo $2^{\circ}$ - Con este fin se faculta al Alcalde y al Personero, a sesorados por la Junta de que se tratará en otra par te de este Acuerdo para proceder a buscar los terrenos para la colo oación de este Parque $y$ de los grupos escolares dichos y una vez que los hayan determinado, la Alcaldia procederá a dictâr el respec que los hayan determinado la por sus linderos y ubicación y radicañ do y concretando en éllos la utilidad páblica declarada por el. Art. 1. de este Acuerdo, para todos los efectos legales posteriores:-

Artfculo $3^{\circ}$ - Dictado el Decreto anterior, el Alcalde y el Persone ro, asesorados por la misma Junta procederán a la ad̆ quisición para el Municipio de los terrenos que fueren necesarios para estos objetos . -

Pardgrafo.- Los lotes pira la construcción de escuelas, serán por lo manos tres, completamente separados y convenientemen tessituados, con áreas no nienores de dos cuadras cada uno y fácilmente accesibles.-m

Articulo $4^{\circ}$ - Las escuelas o agrupaciones escolares que se constru yan sobre cada uno de estos lotes se planificarán dé acuerdo con las especificaciones y sistemas que indique la seccion respectiva del lifinisterio de Educación Nacional.-

Articulo $5^{\circ}$ - Una vez que se disponga de uno por 10 menos de estos tratiar terrenos, el Alcalde y el Personero procederán a con. cherdo con lostrucción de los edificen por el misto Ministerio.-

En el caso de que el Ministerio de Educación no facili marán tare al Municipio esta planificación, procederán o II trat concurso para la confeccion de corme a las tarifas y regla tratar los proyectos y préupestos, conforme a las por ultimo a conment os de la Sociedad Colomblana de Arqu

ol financiamiento de las adquisiciones de 208 Lculo $6^{\circ}=$ Para el financiamiento dere este Acuerdo se faculta al f $A_{1}$ calde y al personero para proceder a vender, ya directamente pre utala judicial, o blén po

a) El lote de propiedad Municipal ubicado. en la carrera 9a. 
entre las calies 18 y la callejuela abierta entre esta calle y la 19;

b) - El terreno y edificto donde estuvo la antigua cárcel y está hoy el Cuartel de la Policla, ubicado en la esqui. na de la calle 20 y la carrera $6 a$. de esta ciudad;

c) - El lote que ocupaba el Circo Bengala;

d) - El lote que forme la mitad de la manzana, es decir con frente a la carrera $5 a$, y comprendida entre esta carrera y las calles 24 y 25 de esta ciudad; y

e) - Cualquiera otros que no tengan destinación especial.-

Articulo $7^{\circ}=$ Los producidos de estas enajenaciones se destinarán a las adquisiciones expresadas en este Acuerdo y si nubiere excedentes se aplicarán a la construcción de escuelos en ios terrenos que se compren para este fin.-

Artlculo $80 .-$ En caso de negoclaciones de conpre-ventn o permuta, del Parque y Escuelas y que estará compuesta de cuatro miembros, nombrado uno por la Alcaldia, otro por Ia Personería, otfo por la Comisión de Educación y otro por el Ministerio de Educación Nactonal.-

Paragrafoe- Sobre los terrenos beneficiados por el Parque podra an plicarse el impuesto de valorización.-

Articulo $9^{\circ}$ is 81 para la adquisición de terrenos para el Parque $y$ versiones tomádas de dineros provenientes del empréstito o préstamos de que trata el Acuerdo $\mathrm{N}^{\circ}$ del presente ano, la Junta de que trata el articulo anterior podra ser aumentada en dos miembros más, designados por el Banco o entidad prestamista, con sus respectivos suplent est-:

Partgrafo. - Para las necociacionel de venta o enajenación de inmuebles de propiedad munlcipal no se requiere lo intervención de estos dos últimos miembros de la Junta.-

Artfeulo $10^{\circ}$ - Quedan derogadas todas las disposiciones que se husobre el particular.-

Artículo $11^{\circ}=$ Este Acuerdo regirá desde su sanción.-

Dado en Pereira a de fullio de 1.950

Presentado a la consideración del H. Concejo en su

sesion extraordinaria el dia

Municipal.de jullo por el suscrito Alcalde

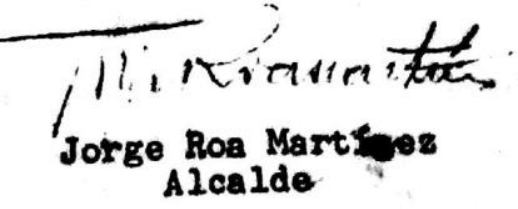

Jie/oov. 